March 2010

\title{
Military Technologies, Nanotechnology and Law: Using Nano-Science Fiction as an Analytical Tool
}




\title{
Military Technologies, Nanotechnology and Law: Using Nano-Science Fiction as an Analytical Tool
}

\author{
[author] ${ }^{1}$ \\ Table of Contents
}

1.0 Law, Science Fiction and Emerging Technologies and the Cautionary Tale

2.0 Crichton, Military Technologies and the Need for Nanodiplomacy

3.0. The maleficent uses of nanoweapons

3.1 The Biological Weapons

3.2 "Born classified" designation.

3.3 The Precautionary Principle

3.4. Global biosecurity codes

3.5. International Environmental Treaties

3.6. Export controls

3.7. Espionage.

3.8. Customary International Law

3.9. The Inner Space

3.10 International Agreement for Domestic Legislation

4.0 The Negligent Use of Nanotechnologies for Military Use

4.1. Laboratory Biosafety and Biosecurity Regulation

4.2 FDA Approval for Human Clinical Trials

4.2.1. Drug approval

4.2.2. Device approval

4.3 Federal Environmental Statutes and Violations

4.3.1. National Environmental Policy Act

4.3.2. Comprehensive Environmental Response, Compensation and Liability Act (CERCLA)

4.3.3. Resource Conservation and Recovery Act (RCRA)

4.3.4. Clean Water Act

4.3.5. Toxic Substances Control Act (TSCA)

4.4 Federal Tort Claims Act

4.5 State Law and Common Law Remedies

5.0 International Law Violations for Xymos

6.0 Nanodiplomacy

7.0 Conclusion author information 


\subsection{Law, Science Fiction and Emerging Technologies and the Cautionary Tale}

The use of science fiction to write cautionary tales of warning or to dream of a better existence for humankind, has lasting and transforming cultural effects. The use of cell phones came much easier after decades of "Dick Tracey" used his two-way wrist watch technology, ${ }^{2}$ transforming culture. Whereas, the reference to Frankenfood, ${ }^{3}$ conjured images of Mary Shelley's Frankenstein and the frightening consequences of biotechnologies which combine parts of nature into one creature or in this case, food, when the term was first used in 1992 as a cautionary neologism. The United States' Strategic Defense Initiative became known as "Star Wars", named after the movie by the same name, released in 1977, and a sequel in 1980, when President Reagan announced it in 1983. And when he used the term the "evil empire" in reference to the Soviet Union in a speech, it became known as the "Darth Vadar speech", in reference to the villain in Star Wars.

Certainly, science fiction writers have been showing the dreams of a better society along with the tales of caution about what they hope to prevent from happening. ${ }^{5}$ Michael Crichton in his novel, Jurassic Park (1990), followed by the movie, Jurassic Park (1993), used then new DNA technologies to depict a nightmarish scenario resulting from its commercial development. Again in a cautionary tale, Crichton, in Prey (2002), described catastrophic consequences of nanotechnologies development for military use, using a term "nanobots" which had been coined around 1989, giving it a more ominous image, when using the term to describe the processes of nanotechnology. ${ }^{6}$ Military nanotechnology which was only experimental, was depicted as unleashed as a military weapon in GI Joe: The Rise of Cobra (2009), where nanobots could be deployed to "eat" a building, which in the movie, depicted the destruction of the Eiffel Tower, by these green nanobots in an attack.

The use of the cautionary tale, is also very useful in the analysis of the emerging technologies which are depicted in these tales, in the context of the legal regulatory framework which currently exists. These analyses can reveal adequacies or gaps in the legal framework, and help to shape recommendations for adequately regulating new technologies, without

\footnotetext{
${ }^{2}$ Garyn G. Roberts, Dick Tracy and American Culture: Morality and Mythology, Text and Context 38 (McFarland \& Co., 2003).

${ }^{3}$ Paul Lewis is credited with coining the neologism, Frankenfood, in a quotation in an article, Molly O'Neil,

"Geneticists' Latest Discovery: Public Fear of 'Frankenfood", The New York Times (June 28, 1992) at http://www.nytimes.com/1992/06/28/us/geneticists-latest-discovery-public-fear-of-frankenfood.html?pagewanted=1. ${ }^{4}$ Frances Fitzgerald, Way Out There in the Blue: Reagan, Star Wars and the End of the Cold War, 21-22 (Simon \& Schuster, 2000).

${ }^{5}$ Heather Urbanski, Plagues, Apocalypses and Bug-Eyed Monsters: How Speculative Fiction Shows Us Our Nightmares 11-13 (McFarland \& Co., Inc., 2007).

6 nanobot. Dictionary.com's 21 st Century Lexicon (2003-2010). dictionary.com, LLC. at http://dictionary.reference.com/browse/nanobot (accessed: March 19, 2010). Definition: Nanobot $n$. a microscopic robot used in nanotechnology, a nano-robot, an extremely small, autonomous, self- pro-propelled machine that may reproduce. Etymology: 1989.
} 
excessively smothering their development before they have an opportunity to improve the existence of humankind.

The use of Michael Crichton's novel, Prey, is a science fiction, cautionary tale about nanotechnologies and their development for military use, which can be very useful in analyzing our regulatory framework for nanotechnologies.

\subsection{Crichton, Military Technologies and the Need for Nanodiplomacy}

The Army is acting dumb about this whole thing, . . I'm not really worried about the Army. I'm worried about Larry Handler and the others at Xymos. They know they have horrific lawsuits on their hands. The company will declare bankruptcy sometime this week, but they're still liable for criminal charges. Larry especially, I wouldn't cry if he went to jail. ${ }^{7}$

This was one of the final paragraphs in Michael Crichton's nanobio-techno-thriller, Prey, which involved a military defense contractor, working for the Army on a secret project to develop roving swarms of nanobots which would act as cameras for purposes of reconnaissance and surveillance. One of the company's executives decided to utilize the nanobots' ability to evolve and to use artificial intelligence to work out some of the glitches, by letting it go into the environment to be free to evolve, setting the stage for the runaway self-replicating, evolving, environmental-contaminating disaster.

While the science in Prey is mostly science fiction, ${ }^{8}$ the legal issues are potentially very real and useful to examine. In the context of nanodiplomacy, the maleficent uses of nanotechnologies for terrorism or warfare purposes must also include the negligent manufacture, storage, testing and experimentation of such nanomaterials and nanodevices by government contractors and governments. In the novel Prey, a defense contractor's actions result in domestic law violations, in addition to international law violations which may be applicable to nanoweapons. The potential liability arises from domestic federal statutory violations of several federal environmental statutes and common law liability. State common law claims against the defense contractor, Xymos, could include criminal and common law negligence. The federal government may not be protected by sovereign immunity.

From the potential threat of nanotechnologies, the potential for nanoweapons raises new considerations for describing their possible scope of action. Knowledge-based mass destruction (KMD), destructiveness hugely amplified by the power of self-replication; and weapons of

\footnotetext{
${ }^{7}$ Michael Crichton, Prey, 497 (2003).

${ }^{8}$ Chris Phoenix, “Don't let Crichton's Prey scare you --- the science isn't real," Center for Responsible Nanotechnology, 7thWave, Inc. (Jan 2003) at http://www.nanotech-now.com/Chris-Phoenix/prey-critique.htm .
} 
global destruction (WGD) are terms coined by Sean Howard ${ }^{9}$ to describe the potential of nanotechnologies.

This article begins where Crichton stops, with the spectre of litigation facing Larry Handler and Xymos, Inc., introduced in part one. The second part, provides an overview of the characterization of nanotechnologies and the problem with not only maleficience but negligence in the research and development stages and an introduction to the scope of international principles and national security law approaches which might be used to address the major, global threat of the maleficent use of nanoweapons. The third part of this examination returns to the Prey scenario to apply legal principles to the facts in the Prey scenario in response to the damages, deaths and destruction resulting from the themes of Prey from the perspective of U.S. domestic law. The fourth part of this examination addresses the application of international law to the Prey scenario, with recommendations for addressing the potential threat of nanoweapons. The fifth part summarizes the use of nanodiplomacy to reach the goals of national and global security.

\subsection{The maleficent uses of nanoweapons}

The threat of nanoweapons is not immediate, but the application of nanotechnologies in warfare and defense may accelerate such dual uses. Currently, the threat of nanoweapons and the technologies to produce them in the hands of a wide range of sovereign to radical groups is about 5-15 years in the future, with a predicted radical advancement. ${ }^{10}$ Altmann predicts these will range from the use of small animals with sensors (birds, rats, fish, insects), nerve/brain contact for movement control, reconnaissance as bio-technical hybrids; and as biological weapons, capsules, active groups for bonding, vectors for entry in body, cell, nanodevices that cross the blood-brain barrier, selective reaction, control of immune reactions and psychological controlling activity. ${ }^{11}$ Reynolds, drawing from experts in 2003, proposed nanoweapons that might induce troops to love each other on both sides of a conflict, or to love a particular political philosophy or a particular government, neurotransmitter levels being controlled by nanodevices, or devices that can induce disease, sitting latent in a body for some time, only to be triggered by an environmental or other external stimuli. ${ }^{12}$

\footnotetext{
${ }^{9}$ Sean Howard, Nanotechnology and Mass Destruction: The Need for an Inner Space Treaty, Disarmament Diplomacy, Opinion and Analysis, No. 65 (July-Aug 2002) (C) 2002 The Acronym Institute at http://www.acronym.org.uk/dd/dd65/65op1.htm .

${ }^{10}$ Jurgen Altmann, Military Nanotechnology: Potential applications and preventive arms control, Routledge 106$108(2006) /$

${ }^{11}$ Ibid.

${ }^{12}$ G. H. Reynolds, "Nanotechnology and Regulatory Policy: Three Futures," Harvard Journal of Law \& Technology 17 (2003): 179-209, 193-194.
} 
In a study survey among experts in 2004, the participant panels were asked what "future applications of science or scientific research that have the greatest potential for danger to human survival?" Among the five applications that were identified as having the "greatest potential for danger to human survival, two of them were specific concerns about nanotechnologies that could be used negligently or for maleficent purposes: "Nanotechnology to build stealthy new means of killing large numbers of people," and "Intelligent nanotechnology evolving beyond human control." In the same survey, it was insightful that nanotechnology was not identified with applications that could "improve the human condition". 14

A working definition for nanoweapons should be the first step of our analysis for purposes of considering a regulatory or analytical framework for law. This is particularly challenging given the uncertainty of the scope and function of the nanotechnologies but also because there are no consensus definitions for nanotechnology. In order to develop a working definition of nanoweapons, a review of definitions can be useful, which include those developed by the Office of Science and Technology Policy, coordinating council NSTC for the National Nanotechnology Initiative, the U.S. Environmental Protection Agency and the U.S. Food and Drug Administration statement on defining nanotechnologies.

The National Nanotechnology Initiative, defines nanotechnology from the perspective of research and development; used a description of form, rather than function:

Nanotechnology is the understanding and control of matter at dimensions of roughly 1 to 100 nanometers, where unique phenomena enable novel applications. Encompassing nanoscale science, engineering and technology, nanotechnology involves imaging, measuring, modeling, and manipulating matter at this length scale. At this level, the physical, chemical and biological properties of materials may differ in fundamental and valuable ways from the properties of individual atoms and molecules or bulk matter. Nanotechnology research and development is

\footnotetext{
13 Jerome Glenn, Theodore J. Gordon, Future S\&T management policy issues-2025 global scenarios, Technological Forecasting \& Social Change 71 (2004) 913-940. The question and responses read as follows: 6. Based on the views of the panels that contributed to this study, the future applications of science or scientific research that have the greatest potential for danger to human survival are: Accidentally or intentionally released genetically modified organisms that have serious adverse consequences for the biosphere; Use of biotechnology to build new kinds of biological weapons of mass destruction; Nanotechnology to build stealthy new means of killing large numbers of people; Loss of biodiversity resulting from aggressive, exclusionary marketing strategies; encouraging the use of genetically altered, patented varieties; and Intelligent nanotechnology evolving beyond human control.

${ }^{14}$ Jerome Glenn, Theodore J. Gordon, Future S\&T management policy issues-2025 global scenarios, Technological Forecasting \& Social Change 71 (2004) 913-940. The question and responses as reported: 5. Based on the views of participants, the challenges that science can pursue to help improve the human condition include: Commercial availability of a cheap, efficient, environmentally benign, nonnuclear fission and non-fossil-fuel means of generating base load electricity, competitive in price with today's fossil fuels; Simple, inexpensive, effective medicines and corresponding delivery systems to treat widespread diseases and epidemics; Improving the efficiency of water use in agriculture by $75 \%$; Climate change-understanding and solutions; and Improvements in early detection and tracking systems of pandemics.
} 
directed toward and understanding and creating improved materials, devices and systems that exploit these new properties. 15

The U.S. Environmental Protection Agency also defines nanotechnology as the subject matter of research and development as follows:

Nanotechnology is defined as "research and technology development at the atomic, molecular, or macromolecular levels using a length of scale of approximately one to one hundred nanometers in any dimension; the creation and use of structures, devices and systems that have novel properties and functions because of their small size; and the ability to control or manipulate matter on an atomic scale. ${ }^{16}$

The U.S. Food and Drug Administration simply declined to develop a definition and instead, made this agency statement:

The Task Force has not adopted a precise definition for "nanoscale materials," "nanotechnology," or related terms to define the scope of its work. The Task Force concluded that it would be most productive to take a broadly inclusive approach in identifying potentially relevant studies, data, and other information. ${ }^{17}$

Nanoweapons should be defined as any nanomaterial or nanodevice that affects biological life, with a rebuttable presumption of dual use for good as well as maleficent purposes. (Seemingly redundant at first glance, biological life is distinct from biological matter, e.g., detritus.) The use of the word bionanoweapons or bionanotechnologies or bionanodevices or bionanomaterials would include only a subset of the potential weapons that can be used to affect biological life, life systems and ecosystems. Biological weapons from a science perspective are typically much larger than nanosize (1-100 nanometers), and almost entirely nonexistent in nature. Almost all nanoweapons exist as a result of a manufacturing or fabrication process, with almost no naturally occurring nanosize materials, devices or biologics.

Emerging technologies are typically examined in the existing framework of statutes and laws, and potential gaps are then examined. Following that analytical protocol, the first question to ask is whether existing arms control treaties are applicable.

Three treaties which are the most relevant and applicable to nanoweapons are the 1968 Nuclear Non-Proliferation Treaty (NNPT), ${ }^{18}$ the 1972 Biological Weapons and Toxins

\footnotetext{
${ }^{15}$ National Nanotechnology Initiative, President's Budget for 2008 at http://www.nano.gov/NNI_08Budget.pdf ..

${ }^{16}$ U.S. EPA Nanotechnology White Paper, EPA 100/B-07/001 February 2007, available at http://www.epa.gov/OSA/pdfs/nanotech/epa-nanotechnology-whitepaper-0207.pdf .

${ }^{17}$ Nanotechnology: A Report of the U.S. Food and Drug Administration, Nanotechnology Task Force, July 25, 2007, at http://www.fda.gov/nanotechnology/taskforce/report2007.pdf .

${ }^{18}$ Treaty on the Non-Proliferation of Nuclear Weapons, opened for signature July 1, 1968, 21 U.S.T. 483, 484, 729 U.N.T.S. 161, 169.
} 
Convention (BWC), ${ }^{19}$ and the 1993 Chemical Weapons Convention (CWC). ${ }^{20}$ The NNPT allows for peaceful uses of nuclear technology, but allows uranium enrichment and acquisition of these materials for nuclear energy, which has dual uses. The industrial equipment required to carry out these processes are large, controlled and not easily hidden, and require very specific knowledge and skills. Even in this limited sphere, nuclear non-proliferation has not been entirely successful, with some key sovereign countries still not parties to the treaty, ${ }^{21}$ like Pakistan and North Korea which have been engaged in open testing of nuclear weapons.

International regulatory approaches to address nanoweapons:

3.1 The Biological Weapons Convention is unique in that it is the only treaty to agree to a complete ban on a class of weapons. However, the difficulty arises with the dual use possibilities of possessing potential biological weapons agents, "in an amount and quantity" not appropriate for research. These agents are small, the equipment is inexpensive, but indicia of this activity is biological reactors, equipment and large storage areas, such as was evident in the Biopreparat offensive program of the former Soviet Union. Adding to the difficulty is that enforcement is limited to self-policing with no agreed inspection protocols, due to the risks of proprietary information that might be accessed during inspections of pharmaceutical companies, for example.

Even with these shortcomings, the utilization of the BWC for control of some classes of nanodevices and nanotechnologies is useful. Triggering the prohibitions of the BWC, are the "development, production, stockpiling, acquisition, or retention of biological weapons or biological agents in types or amounts that are not justified for peaceful purposes." 22 The preamble simply defines them by their use: "bacteriological (biological) agents and toxins being used as weapons". Article 1, of the BWC prohibits "[m]icrobial or other biological agents, or toxins whatever their origin or method of production ..." This definition would encompass anything biological defined by its use, which in its broadest science definition would mean anything containing carbon. This would certainly encompass hybrid nanodevices and nanomaterials, nanotubes made with carbon and graphite nanomaterials or hybrids, such as metals combined with DNA fragments. This might encompass some, but not all nanoweapons, such as those with non-carbon materials, e.g., nanosilver, nanogold materials. The definition of biological might be defined to include biologically-active, which would include anything that reacts or interacts with life or life systems.

\footnotetext{
${ }^{19}$ Convention on the Prohibition of the Development, Production, and Stockpiling of Bacteriological (Biological) and Toxin Weapons and on Their Destruction, opened for signature April 10, 1972, 26 U.S.T. 583, 1015 U.N.T.S. 163.

${ }^{20}$ Convention on the Prohibition of the Development, Production, Stockpiling and Use of Chemical Weapons and on Their Destruction, January 13, 1993, 1974 U.N.T.S. 45, 32 I.L.M. 800.

${ }^{21}$ Other key countries not party to the treaty are India and Israel.

${ }^{22}$ Convention on the Prohibition of the Development, Production, and Stockpiling of Bacteriological (Biological) and Toxin Weapons and on Their Destruction, opened for signature April 10, 1972, 26 U.S.T. 583, 1015 U.N.T.S. 163.
} 
Glenn H. Reynolds, writes that nanotechnological devices are the "functional equivalents of chemical and biological weapons," 23 and this might also be included in the expanded definition of biological weapons.

However, Robert Pinson argues that the BWC and CWC are not adequate to cover nanotechnologies because they are "outdated and were drafted without a major development like nanotechnology in mind. Institutions like the BWC and CWC are already set and cannot be easily adapted to accommodate new advances in technology. In addition, the uses and purposes of nanotechnology are expected to be so diverse that existing regimes cannot properly discern harmful from helpful uses." 24

Gary E. Marchant, describes the use of a number of possible approaches including the application of Non-Proliferation Arms Control Agreements. However, he concludes that it is unlikely that governments will pursue international agreements until nanotechnologies pose a more realistic threat as weapons of mass destruction, "but such possibilities are likely far into the future. .." 25

3.2 "Born classified" designation. ${ }^{26}$ A complete prohibition for use of nanotechnology in the private sector, would require that all activity be classified whether it is work done by the government or by government contractors. With the rapid increase in interest in the private sector, this would be a difficult cultural and economic trend to reverse, and would require draconian governmental prohibitions.

Reynolds writes that because the tools of nanotechnology are primarily computers, "Scanning Tunneling Microscopes and Atomic Force Microscopes,"27 are easily concealed, are relatively small and quiet, they are inexpensive, and laboratories in small spaces and in homes, would make a complete prohibition extremely difficult. However, biological weapons suffer the same set of clandestine circumstances, and a complete prohibition on biological weapons has been federal law since $1989 .^{28}$

3.3 The Precautionary Principle. One definition of the precautionary principle is that "when there is a risk of disaster no action would be permitted that increases that risk." In the case of nanotechnologies, there is very little scientific data to suggest that there is no risk of

\footnotetext{
${ }^{23}$ G. H. Reynolds, "Nanotechnology and Regulatory Policy: Three Futures," Harvard Journal of Law \& Technology 17 (2003): 179-209, 193.

${ }^{24}$ Robert Pinson. Is Nanotechnology Prohibited by the Biological and Chemical Weapons Conventions?, 22 Berkeley J. Int'1 L. 279, 309 (2004). Or

R. D. Pinson, "Is Nanotechnology Prohibited by the Biological and Chemical Weapons Convention?" Berkeley Journal of International Law 22 (2004): 279-309, at 281.

${ }^{25}$ Gary E. Marchant, “Transnational Models for Regulation of Nanotechnology,” 34 J.L. Med. \& Ethics 714-723, 719 (Winter 2006).

${ }^{26}$ G. H. Reynolds, "Nanotechnology and Regulatory Policy: Three Futures," Harvard Journal of Law \& Technology 17 (2003): 179-209, 193.

${ }^{27}$ G. H. Reynolds, "Nanotechnology and Regulatory Policy: Three Futures," Harvard Journal of Law \& Technology 17 (2003): 179-209, 193.

${ }^{28}$ Biological Weapons Act of 1989.
} 
nanotechnologies, and some indication that there is a risk. Applying the precautionary principle, it is evident that nanotechnology development would slow to a halt until all risks had been eliminated.

An example of the precautionary principle is where the European Union has utilized the precautionary principle in international trade to prevent the sale of biotechnology crops in the EU, or their development, which has led to a stifling of scientific research with little benefit. This demonstrates one of the negative effects of the precautionary principle in the context of new and emerging technologies. Since it is very difficult to prove a negative, it is unlikely that the EU will ever have evidence to prove that there are zero risks associated with biotechnology.

Another example of a version of the precautionary principle is the City of Berkeley ordinance, which is intended to regulate the risks of handling and storing nanomaterials. By creating classification categories based on risk assessment, a level of safety is described. Where the risks are unknown, the maximum safeguards are required.

3.4. Global biosecurity codes. The BWC has taken the direction of the development of biosafety and biosecurity codes which address the research and development aspects of biological agents and toxins in order to prevent harm from mishandling. Diplomatic roadblocks to developing an inspection protocol for the BWC, led the delegation in another direction for the domestic regulation of biological agents, especially in the Many nations are currently developing legal structures with registration and inspection protocols for the safe handling and security for biological organisms, based on either a risk category or a list of pre-selected, named biological agents and toxins.

3.5. International Environmental Treaties. Environmental treaties provide for protection of the environment and could apply to nanotechnologies which might risk damage to the environment. Several environmental treaties controlling persistent organic pollutants, or treaties like the Montreal Protocol which regulate specific substances are narrow in their application and may address a very narrow segment of nanomaterials, but as a general matter, these treaties are not useful for controlling the effects or emissions of nanomaterials on the environment.

3.6. Export controls. Currently, NSDD-189 issued by Pres. Reagan addresses the free exchange of fundamental research. Export controls do not prohibit those articles in the public domain $^{29}$; however defense articles $^{30}$ are prohibited for export without a permit. Any thing prohibited for export can also be "deemed export" where a transfer is made to a citizen of a prohibited country for export, when that citizen is in the U.S. when the transfer is made.

In the Prey scenario, there were no attempts to export the nanobots, but whether it would have prohibited by the Commerce Control List in any of

\footnotetext{
${ }^{29} 22$ CFR $\S 120.11$.

${ }^{30} 22$ CFR $\S 120.10$ (5).
}

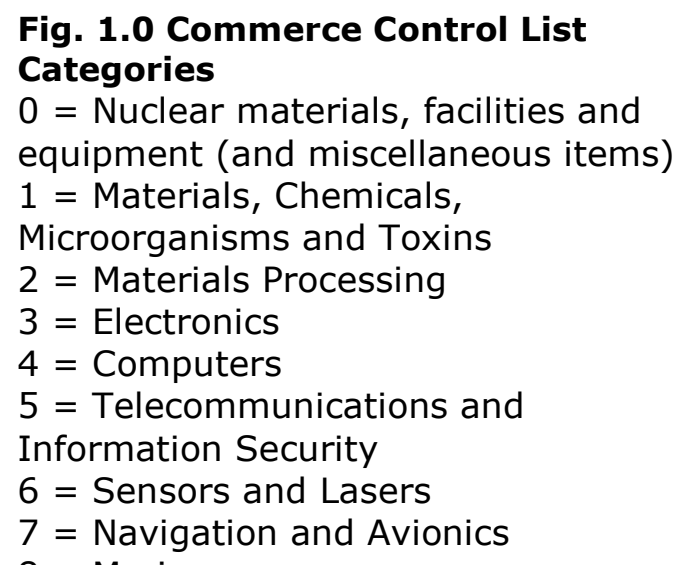


these categories, is doubtful. The term "nano" is

not used in any material listed that is controlled under the Department of Commerce export categories, unless it falls under the category of "toxins" in category " 1 ". The list of categories appears in figure 1.0.

3.7. Espionage. The death penalty may be utilized to punish a person who "communicates, delivers, or transmits, or attempts to communicate, deliver, or transmit, to ..." a foreign government, faction or citizen of another nation, and injuries the United States or advantages another nation. The material transmitted which may encompass nanotechnologies which may be useful in defense or "any other major weapons system or major element of defense strategy," and "the accused shall be punished by death or such other punishment as a courtmartial may direct." 31 The nanobots may be considered useful in defense, even a major element of a defense strategy, making it a controlled material for export.

3.8. Customary International Law. International repeated acceptance of similar international acts over time, would be a form of customary international law. Another type of customary international law is an obligatory act, known as opinio juris. The repeated use of a principle in treaties and agreements is yet another way that a principle assumes the status of customary international law. Another type of customary international law is the preemptory norm, which is a generally accepted norm among most nations, such as the prohibition against genocide, crimes against humanity, slavery. Certainly the maleficent and negligent use of nanotechnologies would very likely be a preemptory norm.

The precautionary principle is becoming a part of customary law by its repeated useage in international treaties and agreements. The use of the precautionary principle would require that nanotechnologies not be permitted unless they could be demonstrated to be safe.

3.9. The Inner Space Treaty. . Sean Howard has recommended an "Inner Space Treaty" which would treat the space where nanotechnologies reside such as inside the human body and inside cells, as a policy space to be regulated with an international treaty. ${ }^{32}$ Howard

${ }^{31}$ Article 106a(D)—Espionage .

32 The features of the inner space treaty of interest are as follows:

(1) The nanotechnological exploration and engineering of inner (atomic and molecular) space shall be carried out for the benefit and in the interests of all countries, irrespective of their degree of economic or scientific development, and shall be the province of all humanity. 
writes that, "Before long, there may be need for an 'inner space' treaty to protect the planet from devastation caused - accidentally, or by terrorists, or in open conflict - by artificial atomic and molecular structures capable of destroying environments and life forms from within."33 The Outer Space Treaty (OST) was established through the United Nations in 1967 in the heat of the "space race" with the purpose of regulating and preserving outer space for peaceful exploration and commercial activities, and Howard seeks to use this as a model for developing an Inner Space Treaty.

In the Prey scenario, there was no suggestion that the nanobots would enter outer space, so the aspects of space law and military technology will not be further examined, although other nanotechnology scenarios may require an examination of this area of law.

\subsection{International Agreement for Domestic Legislation}

The agreement to pass domestic legislation is an important and essential element of regulating the risks of nanotechnologies which may have dual uses. The elements of such as agreement might include: (1) No naturally occurring or uncontrollable feedstocks, e.g., photons, oxygen; (2) No uncontained experiments; (3) INDs category for defensive nano; (4) Regulatory Framework modeled after the Hydrogen Regulatory Framework; (5) Registration of facilities; and (6) Nanomaterials disclosure, modeled after EPCRKA.

\subsection{The Negligent Use of Nanotechnologies for Military Use}

The use of the nanodevice in Prey in the clinical trials on humans for a reconnaissance technology, would have required a number of safeguards be met before the first human trial. The government contractor defense is only available if there is no negligence on the part of the contractor. The failure to seek the proper approvals and violation of the FFDCA statute is prima facie negligence, in general. The first part of this section will examine the potential violation of the FFDCA requirements for nanodevices used with humans; and the second part will be an examination of violations of applicable federal environmental statutes. The next section will examine the common law remedies available for damages by Xymos for their actions or inactions.

(2) Inner space shall be free for exploration and engineering by all states without discrimination of any kind, on a basis of equality and in accordance with international law, and there shall be free access to all areas of the nanosphere.

(3) There shall be freedom of nanotechnological investigation in inner space and states shall facilitate and encourage international cooperation in such investigation.

[The exploration and use of outer space, including the moon and other celestial bodies, shall be carried out for the benefit and in the interests of all countries, irrespective of their degree of economic or scientific development, and shall be the province of all mankind.

Outer space, including the moon and other celestial bodies, shall be free for exploration and use by all states without discrimination of any kind, on a basis of equality and in accordance with international law, and there shall be free access to all areas of celestial bodies.

There shall be freedom of scientific investigation in outer space, including the moon and other celestial bodies, and states shall facilitate and encourage international cooperation in such investigation.

${ }^{33}$ Sean Howard, "Nanotechnology and Mass Destruction: The Need for an Inner Space Treaty," 65 Disarmament Diplomacy (July-Aug 2002) available at http://www.acronym.org.uk/dd/dd65/65op1.htm (site visited 2-21-2009). 


\subsection{Laboratory Biosafety and Biosecurity Regulation}

Research and development is a major part of the nanotechnology commercial and noncommercial activity, which is expected at the start of an emerging technology. For that reason, it is important to focus on the biosafety and biosecurity aspects of nanotechnologies in the laboratory environment. The scenario in Prey, involved the research and development of a nanotechnology which ultimately accidentally or intentionally was released into the environment. Not only was the technology released into the environment, it was also used in human subject testing of the devices, raising human clinical trials questions of compliance. The following discussion and analysis will address those two components of the research and development aspect of the scenario in Prey, beginning with the applicability of current biosafety and biosecurity regulations, for handling, storing and disposing and transporting.

The biosafety and biosecurity regulations which may be applicable to nanotechnology are found at 42 CFR $\$ 73$ which prohibits the possession or use of select agents without registration, background investigations and facility security standards; the NIH recombinant DNA (rDNA) guidelines which require institutional review of the research for safety; and criminal statutes for possession of select agents. All three of these statutes have limited scope, and only nanotechnologies which incorporate DNA fragments from the select agent list, would be included, and any fabrication of such a molecule or device would violate the ban on the production of biological weapons unless it was for the purpose of testing countermeasures. Xymos would not be subject to the NIH guidelines for rDNA unless they are receiving NIH funding, for which there is no evidence in the Prey scenario. The funding for this project is completely supported by the Department of Defense, and as we are told, the entire project will collapse for lack of funding, if DOD ends the project, which they have determined has insurmountable scientific and technological obstacles to completion. The NIH guidelines for recombinant DNA are largely self-regulating, because the institution, in this case, Xymos, would be required to have an Institutional Review Board (IRB) examine their research protocols to determine if appropriate safety procedures were included, and proper safeguards and laboratory equipment was sufficient to meet standards of acceptable biosafety. Even if they were subject to NIH Guidelines, the sanction would be to withdraw NIH funding and perhaps a moratorium on future NIH grants for a specified period.

The utilization of the BMBL for biological safety laboratories, provides guidance based on risk assessments of the biological materials. This guide is adopted by reference, in the regulations for biosafety and biosecurity in the laboratory, but it is not binding for purposes of regulatory enforcement. The BMBL however, could be utilized as a guide for determining laboratory infrastructure in working with nanomaterials. The penalty for not complying with the BMBL, may result in a suspension of registration to work with biological materials, if subject to the select agent regulations, but these nanobots depicted in Prey would not be subject to the select agent regulations, as discussed above.

Ideally, advances with identification technology which cannot be removed or lost in biological replication, should resolve some of the biosecurity issues working with 
nanotechnologies, for example pioneering work is being done to engineer a DNA nanobarcode to track bacterial populations in agriculturally important microbial environments. ${ }^{34}$

\subsection{FDA Approval for Human Clinical Trials}

\subsubsection{Drug approval}

May 7, 2004, the FDA issued notice of a regulation to assign applications based on the "primary mode of action" to a lead center for this combination product. ${ }^{35}$ The regulation defines the primary mode of action as "the single mode of action of a combination product that provides the most important therapeutic action of the combination product."

The nanobots as they are described in Prey, were initially injected in humans, as described in the early demonstration of a clinical trial at Xymos. Regulation as a biologic, device or combination would be determined by the "mode of action that provides the most important therapeutic action of the combination product." A lead center would be selected, and an application for an Investigational New Drug ${ }^{36}$ would be required before any human studies could begin. Assurances of safety, supported by accompanying pharmacological and toxicological studies of the product in animals is required before FDA can permit human studies. $^{37}$ Testing, using radiolabeled biodistribution for nanotechnologies for first-in-human trials is recommended, calculating a "diagnostic dose," "without therapeutic intent" for the IND, Phase I. ${ }^{38}$ During the period, Phase II requires that studies for safety and efficacy be done with the human studies, and in Phase III, more sensitive populations are tested or excluded from possible use of the product based on safety or efficacy, or the purpose of the product.

After completing Phase I, II and III and safety is assured for human studies, Xymos would have to file a New Drug Application (NDA) in order to obtain an approval for marketing the product. ${ }^{39}$ More data is required, including the results of the IND studies, animal pharmacology and toxicology studies, bioavailability data, and extensive data on safety and efficacy generated in the human studies.

An application could also be made for an abbreviated new drug application (ANDA) for a previously approved product, but these nanobots are clearly not a candidate for this status.

\subsubsection{Device approval}

\footnotetext{
${ }^{34}$ Dr. Dan Luo, Cornell University as described by Karen Hunter, Program Specialist, USDA, at the $1^{\text {st }}$ Annual FDLI Nanotechnology Conference, Feb. 28, 2008, Washington, D.C.

3570 Fed. Reg. 49848-49862 (Thursday, May 7, 2004).

3621 CFR $\$ 312$

${ }^{37}$ Task Force for Review of Nanotechnology and FDA, Nanotechnology: A Report of the U.S. Food and Drug Administration, Nanotechnology Task Force, July 25, 2007.

${ }^{38}$ George Mills, Perceptive Informatics, Inc., Testimony, FDA Hearing at http://www.regulations.gov/fdmspublic/component/main?main=DocumentDetail\&o=0900006480706956 (Sept 15, 2008) .

393921 CFR $\S 314.50$.
} 
Medical devices are regulated under the FDCA, and they are classified according to a risk on a three level system: Class I, II, and III. Class I devices are considered to be low risk, with well established safety and effectiveness data. Registration of a Class I device, generally includes only labeling, good manufacturing practices (GMP) and adverse event reporting. Class II devices are more risky and are typically more complex. A pre-market notification (PMN) is required for these devices, called a 510(k) submission. Data which demonstrates that the applicant device is "substantially equivalent" to another device already on the market, is required with this device category. This data would include pre-clinical data such as animal toxicology tests, and human clinical data, and human population data.

The FDA permits modifications to Class II devices without further approval or without resubmitting a 501(k) application, unless they involve, for example, fundamentally different science or technology. In the case of nanotechnology, where nanosize materials may have vastly different characteristics, but are used in existing and approved Class II devices, manufacturers will be required to resubmit an application. ${ }^{40}$

The Class III device is the most complex with the highest risk among the devices, and require pre-market approval, manufacturing inspection and the submission of periodic reports. Data that must be submitted with the pre-market approval (PMA) include a description of the device and its intended use, and chemical and physical composition of the materials making the device. For human trials purposes, the Class III device must be an approved investigational device exemption (IDE), ${ }^{41}$ analogous to the IND status of a drug, while it is undergoing human trials. The Class III device poses a "significant risk" which is one which poses "a serious risk to the health, safety or welfare of a subject."

The FDA provides guidance on how to determine whether a device is one with "significant risk", in implementation of regulation. ${ }^{42}$ The criteria in the guidance which explain 21 CFR 812.3(m), in general, cover devices which "present a serious risk to the health, safety, or welfare of a subject." 43

The responsibilities of the sponsor of the research of these Class III, "significant risk" devices include advising its clinical investigators of the status and obtaining their express acceptance of the regulations. ${ }^{44}$ The device study must be approved by an Institutional Review Board (IRB) prior to approval of the study by the U.S. FDA. ${ }^{45}$ The IRBs must consider a number of factors in making their determination, including what is the nature of the harm that

\footnotetext{
${ }^{40}$ Task Force on FDA and Nanotechnology, Nanotechnology: A Report of the U.S. Food and Drug Administration Nanotechnology Task Force, July 25, 2007.

41 CFR $\$ 812.20$.

42 CFR 812.3(m).

${ }^{43}$ The guidance criteria for identifying a device which should be classified as one with "significant risk": "(1) Is intended as an implant and presents a potential for serious risk to the health, safety, or welfare of a subject; (2) Is purported or represented to be for use supporting or sustaining human life and presents a potential for serious risk to the health, safety, or welfare of a subject; (3) Is for a use of substantial importance in diagnosing, curing, mitigating, or treating disease, or otherwise preventing impairment of human health and presents a potential for serious risk to the health, safety, or welfare of a subject; or (4) Otherwise presents a potential for serious risk to the health, safety, or welfare of a subject."

${ }^{44} 21$ CFR $\S 812.43$ (c )(4)(i).

4521 CFR $\S 56.108$.
} 
might occur from use of the device and will additional procedures be required as part of the investigational study, which would increase the risk? ${ }^{46}$

Criminal sanctions under the Federal Food, Drug and Cosmetic Act (FDCA) require notice to the subject of the sanction, before referral to the U.S. Department of Justice for prosecution.

International controls on imported cosmetics may be of increasing concern because of the possibility of using nanoparticles for maleficent purposes in handcream, for example. Nanoparticles that penetrate the dermis could cause injury, death or at some time after a period of latency, trigger the maleficent effect of the nanoparticles which penetrated the skin at an earlier time.

\subsection{Federal Environmental Statutes and Violations}

The nanobot scenario unfolds in Prey, with some discussion about why the plant is in Nevada, rather than California where the corporate headquarters is located. It becomes evident that they want "fewer regulations, easier inspections" 47 in Nevada as compared to California. Xymos, however, will have all of the major federal environmental statutes with which to comply, in any state, and these carry significant civil and criminal penalties for their violation.

In general, criminal money sanctions for violation of environmental statutes are on average $\$ 10,000$ or less. The largest fine ever levied was against Exxon for $\$ 25$ million in criminal fines plus $\$ 100$ million in restitute for cleanup in Alaska, made to the state of Alaska and the federal government. Prison sentences are made for environmental crimes for knowing violations. A study of sentencing of individuals for environmental crimes between 1985-1990, showed that civil fines exceeded the criminal fines, suggesting that federal environmental statutes are not the best policy solutions where a criminal penalty is needed.

Civil penalties are much more likely, but more difficult to collect where the company is insolvent. In Prey, at the end, we are told by Jack Forman that "The company will declare bankruptcy sometime this week., but they're still liable for criminal charges." ${ }^{48}$ However, bankruptcy will not shield the corporate officers from liability under some federal environmental statutes, and civil penalties are $\$ 25,000$ per day, for each violation, in addition liability for the costs of cleanup and other related costs.

The violations and possible penalties, both civil and criminal are discussed for each major federal environmental statute, applying them to the facts in Prey.

\subsubsection{National Environmental Policy Act}

Compliance with federal environmental statutes for Xymos in the production of the nanobots or other nanodevices that were expected to be experimented with in open field testing, or the construction of the laboratory where such testing would pose a threat of release to the

\footnotetext{
${ }^{46}$ U.S. FDA, "Information Sheet Guidance for IRBs, Clinical Investigators, and Sponsors Significant Risk and Nonsignificant Risk Medical Device Studies," at http://www.fda.gov/oc/ohrt/irbs/devrisk.pdf .

${ }^{47}$ Prey, 145.

${ }^{48}$ Prey, 497.
} 
environment would require an Environmental Impact Statement (EIS) under the National Environmental Policy Act (NEPA). The threshold requirement to trigger the statute is "any major federal action significantly affecting the quality of the human environment." 49 The Department of Defense would have been responsible for an EIS as a federal agency awarding a defense contract, if an Environmental Assessment (EA) indicated that there would likely be environmental impacts. The process of considering the impacts to the environment as well as considering alternatives would be required under the statute. In Prey, ${ }^{50}$ Jack Forman, our narrator, asks, "Why the hell did they put it in Nevada, anyway?" and the response from "Growly" was it was because " Fewer regulations, easier inspections. These days California is sticky about new industry. There was going to be a year's delay just for environmental-impact statements. And a far more difficult permitting process. So they came here.'"

The next statement from Growly indicates that he may not have considered the environmental impacts as he was designing the project when he said, "Growly looked out the window at the desert. "What a shithole," he said. 'I don't give a fuck what goes on here, it's not a problem.", The NEPA process is only useful because it involves public involvement in the consideration of the impacts, and by moving to Nevada, Xymos has a much smaller immediate population density and less environmental activism compared to California in sheer numbers, alone. For this reason, the federal environmental NEPA process could likely be much faster in Nevada, because delays for more research on the impacts, more input from the public, and revising the EIS with supplemental information are all possible outcomes in any NEPA process, and more likely in California to pose a delay as suggested by "Growly".

It is the Department of Defense which is responsible for the EIS, but in practice, these EISs are part of the work of the government contractor which is developing the project. This does not eliminate the requirement that environmental impacts must be considered at the first contemplation of the project before there are any "irretrievable resources" committed to it. Should the court have evidence such as Growly's statement that his was not done by DOD, what would be the penalty? The penalties for failing to comply with NEPA might be an injunction to stop the project until an EIS is properly done, to require that a new EIS be done, or that a supplemental EIS be done. The only real penalties for Xymos in these cases would be the delay that is feared by Growly. In summary, at the close of Prey, failure to comply with NEPA would not result in civil or criminal penalties based on the statute, but it could serve as prima facie evidence of intent for a state negligence action.

\subsubsection{Comprehensive Environmental Response, Compensation and Liability Act (CERCLA)}

The Superfund Act, or CERCLA, is one of the most powerful environmental statutes for purposes of liability. Hugely controversial when it was first introduced as legislation, it provides for liability for corporate officers, and the ability to "pierce the corporate veil". It also provides for a strict liability scheme based on the common law negligence principle of "abnormally dangerous activities," which could describe work with hazardous substances. Further, the statute also includes a "joint and several liability" provision which makes any one polluter, responsible for the entire cleanup, if necessary to achieve the cleanup of the environment.

\footnotetext{
${ }^{49} \$ 102$ NEPA.

${ }^{50}$ Prey, 145.
} 
Whether CERCLA is triggered by the facts and the nanotechnologies in Prey requires that the question of whether these nanobots would be "hazardous waste" under the CERCLA statute. The CERCLA definition of hazardous substances is defined under the act as any substance "when released into the environment may present substantial danger to the public health or welfare of the environment." broadly, and has included for example, anthrax spores, in the cleanup of the post office in Flordia which had received the anthrax letters for processing in the fall of $2001 .^{52}$ We know that when released into the environment, the nanobots killed rabbits, coyotes and humans, which would support the conclusion that the nanobots would be a "hazardous waste" under CERCLA.

If there has been a "release" under the statute, which has been admitted by the potentially responsible parties (PRP), the statutory term for the polluters who released the hazardous substances, then a removal action is then triggered by the statute. The removal may be either an emergency removal or the contaminated site may be nominated as a Superfund site.

Xymos and the corporate officers would be liable for the "costs of removal or remedial action" incurred by the federal government, "other necessary costs of response" incurred by any other person, and "damages for injury to, destruction of, or loss of natural resources, including the reasonable costs of assessing such injury, destruction, or loss"

The Superfund Amendments and Reauthorization Act (SARA) amended CERCLA to include among other features, the provision to require ongoing health assessment costs for community residents who may have been exposed to the hazardous substances. These are costs that are also recoverable under Superfund. Any visitors to the park, campers, etc. who may be in what is determined to be the contaminated area for purposes of the Superfund cleanup, could be offered ongoing medical surveillance at no cost to them, for their exposures. Individual medical costs for medical monitoring beyond that expected for the community, is not recoverable under Superfund. ${ }^{54}$

Adjacent private property owners, may rightly be concerned that their property values will be negatively affected by the Xymos disaster; however, private individuals cannot recover for lost property values. ${ }^{55}$

Injury to natural resources in the area where the swarms occurred or may still occur, the damage from the nests and the destruction to the habitat are potentially recoverable damages for liability under Superfund. ${ }^{56}$ The costs are owed to the United States government as well as to the

\footnotetext{
5142 U.S.C. $\$ 9602(a)$.

${ }^{52}$ Smith v. Potter, 2001 U.S. Dist. LEXIS 18625 (S.D.N.Y. Nov. 16, 2001); and Smith v. Potter 2002 U.S. Dist. LEXIS 11878 (S.D.N.Y. July 1, 2002).

${ }^{53}$ Sec. $107(\mathrm{a})$.

${ }^{54}$ Price v. U.S. Navy, 39 F.3d 1011 (9 $9^{\text {th }}$ Cir. 1994).

${ }_{55}$ Price v. U.S. Navy, 39 F.3d 1011 (9 $9^{\text {th }}$ Cir. 1994).

56 CERCLA $\$ 107(f)$.
} 
state for "within the State or belonging to, managed by, controlled by, or appertaining to such State," and to any Indian tribe. ${ }^{57}$

However, all of the threshold requirements discussed above will be irrelevant, if the amount of the hazardous material does not meet the threshold minimum amount. In settlement agreements with the potentially responsible parties (PRPs) ${ }^{58}$ For example a de minimus settlement would provide for expedited settlements for small-volume waste, ${ }^{59}$ while a de micromis exception (for less than 110 gallons or 200 pounds of hazardous substances) ${ }^{60}$ would provide a liability-free settlement. CERCLA does provide for smaller quantities of hazardous materials specifically listed as ultra hazardous substances under CERCLA, but no nanotechnologies have been listed. Given the weight of the nanobots, it is almost certain that the threshold quantity of a hazardous substance will not be met under CERCLA, and Xymos and Larry Handler will escape liability for the environmental cleanup costs, and the ongoing medical surveillance costs.

\subsubsection{Resource Conservation and Recovery Act (RCRA)}

The RCRA, is the federal environmental statute for regulating the handling, transportation and storage of hazardous wastes. If hazardous materials are generated, transported, stored or disposed without the RCRA manifest completed with the required lifecycle information for that specific quantity of material, fines of $\$ 25,000$ per day are permitted for knowing violations. ${ }^{61}$

"Knowing" for purposes of RCRA, has been interpreted broadly, and in one case, the jury was instructed to decide whether the defendant was found to have knowingly disposed of creosote sludge and knew that it "had the potential to be harmful to others or the environment or, in other words, it was not a harmless substance like uncontaminated water." 62

Further, what has become recognized as the "public welfare offense" doctrine, which holds that when knowledge is an element of a statute, which is intended to regulate hazardous substances, the knowing element is satisfied upon a showing that the defendant was aware that he was performing the proscribed acts and knowledge of the regulatory requirements is not a prerequisite. $^{63}$

Given the statements of Larry Handler, CEO of Xymos, Inc., it is apparent that he was aware of the damage to the environment when he remarked to Jack Forman, "Growly looked out

${ }^{57}$ Ibid.

${ }^{58}$ CERCLA §122(a) settlement agreements.

${ }^{59}$ CERCLA $\$ 122(\mathrm{~g})(1)$ de minimis stettlements.

${ }^{61}$ RCRA $§ 3008(d)$ fines and imprisonment for any person who:

(1) knowingly transports or causes to be transported any hazardous waste identified or listed under this subchapter to a facility which does not have a permit under this subchapter. . .

(2) knowingly treats, stores, or disposes of any hazardous waste identified or listed under this subchapter ---

(A) without a permit under this subchapter ...;

(B) in knowing violation of any material condition or requirement of such permit . .

${ }_{63}^{62}$ US v. Laughlin, 10 F.3d 961 (2d Cir. 1993).

63 U.S. 
the window at the desert. "What a shithole," he said. "I don't give a fuck what goes on here, it's not a problem." ${ }^{64}$ Further, the CEO also directed his employee to coverup and deny the environmental damage done by the nanobots, knowing there had been an accidental release: "Hell, I wouldn't play it that way," said growling voice. "We're better off flatly denying it. Nothing was released. I mean, what's the evidence anything was released?"65 Later, we discover that the release into the environment may have been intentional, at the direction of the Vice President of Xymos, Inc., Julia Forman.

\subsubsection{Clean Water Act}

The element of "knowing" is also required for civil penalties under the Clean Water Act. ${ }^{66}$ A permitee can be punished who "knowingly violates" a condition or limitation contained in a permit. In a prosecution under the Clean Water Act for criminal penalties, the jury was instructed that in order to find the defendant guilty of acting "knowingly" that the proof had to show that he was "aware of the nature of his acts, perform[ed] them intentionally, and [did] not act or fail to act through ignorance, mistake, or accident." The jury instruction was upheld, finding that the government was not required to prove that the defendant knew that his acts violated either the CWA or the NPDES effluent discharge permit, issued under the Clean Water Act, "but merely that he was aware of the conduct that resulted in the permit's violation."67 Further, negligence can also result in a conviction under the Clean Water Act, where the defendant negligently discharged oil into a navigable water of the United States ${ }^{68}$ with "failure to use reasonable care," 69 resulting in a conviction.

In Xymos, Inc. the plant is located in the desert, and no navigable water is at risk; however, groundwater might be affected as a result of the nests that were built by the nanobots which were underground. Although, there is evidence of a knowing contamination of groundwater, groundwater is not within the scope of the Clean Water Act, and no violation for this damage would be available under this Act.

\subsubsection{Toxic Substances Control Act (TSCA)}

The statute is designed to protect against the manufacture and sale of any new substance that "might pose a threat may present an unreasonable risk of injury to health or the environment"70 The Act also requires that no "new substance" may be manufactured without notifying EPA within 90 days in advance that the new substance will not present an unreasonable risk. $^{71}$ The U.S. EPA, Office of Toxics has recently published notice, ${ }^{72}$ that nanocarbontubules may be a "new substance" requiring demonstration that there is no "unreasonable risk."

\footnotetext{
${ }^{64}$ Prey, 145.

${ }^{65}$ Prey, 144.

${ }^{66}$ CWA $\$ 309$ (c )(2)(A).

${ }^{67}$ United States v. Sinskey, 119 F.3d $712\left(8^{\text {th }}\right.$ Cir. 1997).

${ }^{68}$ CWA 309 (c )(1)(A) and 311(b)(3).

${ }^{69}$ United States v. Hanousek, 176 F.3d $1116\left(9^{\text {th }}\right.$ Cir. 1999) cert denied, 528 U.S. 1102 (2000).

${ }^{70}$ TSCA $\S 4$.

${ }^{71}$ TSCA $\S 5$.
} 
In addition, if a manufacturer discovers that there is a "substantial risk", they must report it to the U.S. EPA. ${ }^{73}$ This was clarified as the "substantial risk policy," $" 74$ and has applicability to nanotechnologies.

There is no evidence indicating that Xymos, Inc. filed either a Pre-Manufacturing Notice (PMN) required by TSCA,${ }^{75}$ or certainly did not give the required notice to the U.S. EPA upon learning that the "new substance", the nanobots, posed a "substantial risk" 76 after the release of the nanobots into the environment, and the ensuing damage to the coyotes, rabbits and nesting damage to the desert.

\subsection{Federal Tort Claims Act}

The Federal Tort Claims Act ${ }^{77}$ requires that for the federal government to be liable for negligence, it must be:

... caused by the wrongful act or omission of any employee of the Government while acting within the scope of his office or employment, under circumstances where the United States, if a private person, would be liable to the claimant in accordance with the law of the place where the act or omission occurred.

In United States v. Stevens, ${ }^{78}$ the widow of the first victim of the anthrax attacks of fall 2001, succeeded on an interlocutory appeal on the "law of the place" which is Florida, where her husband, Robert Stevens, died as a result of opening an envelope contained anthrax which is alleged to have originated in a United States government laboratory, USAMRIID, in Maryland. Due to the negligence of the United States and the government contractor, Batelle Memorial Institute, which managed the facility, the complaint alleges the anthrax was permitted to be taken due to inadequate safeguards on the biological material. The case was decided October 30, 2008 after the F.B.I. revealed that their sole suspect was a senior anthrax researcher at USAMRIID in August 2008.

The court held that "no special relationship" between the perpetrator of the mailing of the anthrax and the laboratory was required to be shown; and also that "the laboratory owed a duty of care to members of the general public to avoid an unauthorized interception and dissemination of the ultrahazardous materials." The court analyzed the negligence claim by examining the "foreseeable zone of risk" as the test to determine whether there is an underlying legal duty to avoid injury to others. The Florida Supreme Court looked to the Restatement of Torts ${ }^{79}$ for

72 _Fed Reg. ___ (Oct 31, 2008).

${ }_{73}$ TSCA $\S 8(\mathrm{e})$.

74 Fed. Reg.___ (June 2, 2003).

75 TSCA $\S 5$.

76 TSCA $\$ 8(\mathrm{e})$.

7728 U.S.C. $§ 1346(\mathrm{~b})(1)$.

78994 So.2d 1062 (Fla. 2008).

${ }^{79}$ Restat. (Second) of Torts (1965) \$302 Risk of Direct or Indirect Harm. A Negligent act or omission may be one which involves an unreasonable risk of harm to another through either (a) the continuous operation of a force started or continued by the act or omission, or (b) the foreseeable action of the other, a third person, an animal, or force of nature." 
guidance and concluded that "a laboratory that manufactures, grows, tests or handles ultrahazardous materials does owe a duty of reasonable care to members of the general public to avoid an unauthorized interception and dissemination of the materials." 80

In the case of Xymos, Inc., the "law of the place where the acts or omissions occurred" would be Nevada where the laboratory was located, and the corporate headquarters, California. Being informed by United States v. Stevens, the court would likely look to the Restatement of Torts for guidance, in addition to state law to determine whether the government and its contractor Xymos, Inc. would be liable under the FTCA. Applying the rule that "a laboratory that manufactures, tests or handles ultrahazardous materials does owe a duty of reasonable care to members of the general public ..." would suggest that Xymos, Inc. and the federal government would at least proceed to trial to determine proximate cause.

\subsection{State Law and Common Law Remedies}

The potential tort law remedies that might be available in Nevada, and in California, the state of the corporate headquarters, would include public nuisance, ${ }^{81}$ private nuisance, trespass, strict liability, emotional distress, ${ }^{82}$ enhanced risk of future illness and medical monitoring. ${ }^{83}$

Strict liability for damages can be found where the activity is "abnormally dangerous", where the probability and severity of any foreseeable harm, and it is in an unusual or inappropriate location. ${ }^{84}$ Where an abnormally dangerous activity resulted in toxic substances escaping from a landowner's property, the court imposed strict liability on the defendant. ${ }^{85}$ In Xymos, Inc., the activities could be determined to be "abnormally dangerous" although the location was appropriate given the isolation of the facility away from densely populated human communities. However, the severity and foreseeability of the harm is likely significant enough, to merit the court finding that Xymos, Inc. was engaged in an abnormally dangerous activity. In fact, the Restatement indicates that "risk of physical harm" can be indicate an activity is an "abnormally dangerous activity" "(1) because the likelihood of harm is unusually high or (2) because the severity of the harm could be enormous." 86

Injuries to the humans may also pose potential liability to Xymos, Inc. under the "discovery rule" which states that the period of the statute of limitations does not begin to run until the plaintiff discovers the illness, and if the statute of limitations is three years, then the

Restat. (Second) of Torts §302A. Risk of Negligence or Recklessness of Others. AN act or an omission may be negligent if the actor realizes or should realize harm to another through the negligent or reckless conduct of the other or a third person.

Restat. (Second) of Torts §302B. Risk of Intentional or Criminal Conduct. An act or an omission may be negligent if the actor realizes or should realize that it involves an unreasonable risk of harm to another through the conduct of the other or a third person which is intended to cause harm, even though such conduct is criminal.

${ }^{80} 994$ So.2d 1062, 1070 (Oct. 30, 2008).

${ }^{81}$ Cf. Village of Wilsonville v. SCA Services, Inc., 426 NE2d 824 (Ill. 1981) where the court ordered the removal of a "prospective nuisance."

${ }^{82}$ Cf. Branch v. Western Petroleum, Inc. 657 P.2d 267 (Utah 1982).

${ }^{83}$ Cf. Ayers v. Township of Jackson, 525 A.2d 287 (NJ 1987).

${ }^{84}$ Restatement (Second) Torts sec. 520 (1977).

${ }_{85}^{85}$. State, Dept of Environmental Protection v. Ventron Corp., 468 A.2d 150 (NJ 1983).

${ }^{86}$ Restatement (Third) of Torts sec., Liability for Physical Harm, Chapter IV, sec. 20. 
three years does not begin to run until discover. However, ten states have adopted the "date the plaintiff knew (or reasonably should have known) that the damages were caused by the hazardous substance, ${ }^{87}$ which is the standard in CERCLA.

\subsection{International Law Violations for Xymos}

The Biological Weapons Convention prohibits parties "never in any circumstances to develop, produce, stockpile or otherwise acquire or retain: (1) microbial or other biological agents, or toxins whatever their origin or method of production, of types and in quantities that have no justification for prophylactic, protective or other peaceful purposes; (2) weapons, equipment or means of delivery designed to use such agents or toxins for hostile purposes or in armed conflict." 88 This definition requires a biological component, in the case of a nanotechnology. In Prey, Xymos, Inc. designed a nanobot using the rDNA from a bacteria to design and manufacture the surveillance cameras. They were not designed as a weapon, but rather a surveillance tool, and "equipment" in part two, is among a list of possible covered categories which are prohibited.

International common law has adopted a standard of the "precautionary principle" which generally requires that any risk or an unknown risk is an unacceptable one, and the activity should be prohibited. However, the application of international law would not become an issue, unless the nanobots entered the jurisdictional space of another country, and damages resulted.

Given these potential categories under international law, Xymos, Inc. may face a specially convened international court under the direction of the United Nations to consider the liability of Xymos. However, the International Criminal Court could convene for war crimes not otherwise prohibited in any treaty if warranted. Until the nanobots created by Xymos affect another sovereign, the risk of international law violations are only speculative.

\subsection{Nanodiplomacy}

A neo-Kantian approach to international affairs using a law and ethics approach, is the basis for nanodiplomacy. In contrast, a neo-Hobbesian approach would require strict controls on the research and development of such technologies, much like the nuclear technologies approach. The following discussion of the uniqueness of nanotechnologies demonstrates why a neoKantian approach is more likely to be successful than a strict, neo-Hobbesian approach.

The term "nanodiplomacy" (rather than meaning very small diplomacy) is meant to describe the unique aspects of diplomacy which involve nanotechnologies. One of the unique

\footnotetext{
${ }^{87}$ CERCLA $\S 309$ adopted by state law in ten states, that any action brought under state law for personal injury or property damages "which are caused or contributed to by exposure to any hazardous substance . . released into the environment from a facility," will trigger the commencement of the statue of limitation period on "the date plaintiff knew (or reasonably should have known): that the injury or damages were caused or contributed to by the hazardous substance.

${ }^{88}$ Biological Weapons Convention, Art. I.
} 
factors is that these technologies defy being in any one of the categories which have been traditional ones for diplomacy - health, environment, weapons or trade, evading capture under any single existing international legal instrument. Another unique factor is that they have both benevolent as well as maleficent uses, which are common to biological, chemical and nuclear weapons, but quantities (chemical, biological and nuclear) are indicators of the intent of these uses where large quantities would raise suspicion about their intended uses; whereas nanotechnologies are always in small amounts, obscuring their intended purposes. Another factor is the tracking of chemical, biological and nuclear weapons can be trailed using equipment clues, because these types of weapons are made with specialized equipment. Nanotechnologies are primarily designed with computer equipment, which blend faultlessly with this globally common, ubiquitous technology.

The control of the threat of nanoweapons is dependent upon nanodiplomacy of goodwill, sharing technology and information and technology transfer and benefit sharing, while engaging in a dialogue and development of codes of conduct. These codes of conduct will become the international norm for acceptable conduct by nations. To that end, every diplomatic mission should be briefed on the principles of nanodiplomacy as well as the urgency with which this will be required of us in the next decade.

\subsection{Conclusion}

While the threat of nanoweapons is probably 10-15 years away, even a low risk even will have high level consequences, requiring the global community to consider measures to control the risks. Given the broad range of uses, applications and characterizations of nanotechnologies and both the beneficial as well as maleficent uses, control of the risks in international trade, research and handling makes it uniquely difficult. The use of a neo-Kantian approach using law and ethical approaches through first focusing on domestic law approaches and global ethical approaches is the most likely one to succeed, giving rise to the term nanodiplomacy. 